\title{
SYSTEMATIC LITERATURE REVIEW OF THE EFFECTS OF CLINICAL MENTORING ON NEW GRADUATE REGISTERED NURSES' CLINICAL PERFORMANCE, JOB SATISFACTION AND JOB RETENTION
}

\author{
Jo-Anne Marie Vidal', Richard Olley² \\ 1. NSW Health Vaccination Centre, Sydney, Australia \\ 2. School of Medicine, Griffith University, Queensland, Australia
}

Correspondence:joanne.vidal@health.nsw.gov.au

\section{ABSTRACT}

\section{OBJECTIVE}

The purpose of this systematic literature review is to appraise contemporary research literature examining the effects of mentoring on graduate registered nurses' transition to practice objectively and systematically. These areas, specifically examined, are competence, job satisfaction, and retention. Three themes emerged from the research in this area. The themes are informal mentoring effectiveness, the extent of mentoring, and mentoring efficacy.

\section{METHODS}

The PRISMA method was implemented. Articles reviewed were writtenin English and published between December 2015 and December 2020 and obtained from the Griffith University Library electronic catalogue. A quality assessment of each record not excluded in the title and abstract analysis was undertaken using the method described by Kmet.[1] Those with a quality rating of 16 as a minimum are included in this systematic literature review.

\section{RESULTS}

Three quantitative, two qualitative and two - method research studies emerged after applying inclusion criteria, selection, and quality assessment. The analysis demonstrated the positive effects of mentoring on all three avenues with one mixedmethod study that documented a downward trend in job satisfaction at six months.

\section{CONCLUSIONS}

Mentoring is an effective transition to practice strategy for novice nurses. It affects competence, job satisfaction and retention positively. Retention and resignation rates worsen following 12 months of employment. Robust and rigorous studies are essential to justify long-term mentoring programs' cost-effectiveness.

What is known about the topic? Upon joining the nursing workforce, many new graduate nurses
require adequate training and experience. A failure in this area increases the risk of "reality shock" and
stress which can add to the risk of attrition and turnover. Mentoring is an effective transition to practice
strategy for novice nurses; by bridging the gap between theory and practice. Mentoring improves clinical
performance, job retention and satisfaction within 12 months.
What does this paper add? New graduate mentoring is a recently-documented method in nursing.
Generational mentoring approach acknowledges workplace generational differences and develops
future mentors. This also introduced diversified communication channels between mentors and
mentees, which facilitates seamless communication. Delineations are evident in the literature. These
include distinguishing mentorship from precepting; and turnover from retention. Role demarcations
between preceptor, mentor, and facilitator are also noted. Retention rates dwindle at second year of
mentoring and then challenges the cost-effectiveness of mentoring after 1 year of implementation.
What are the implications for practitioners? There is research paucity regarding the recommended
frequency, structure, duration and content of mentoring programs for new graduate registered nurses
(NGRN's). Furthermore, no qualitative research is found to explore the influential factors that contribute
to career change or resignation of novice nurses after 12 months of transitioning into practice. Nor is
any quantitative research available to measure the effectiveness and practicality of mentoring
programs. Empirical evidence would assist nurse managers and nurse mentors to formulate the
strategies to facilitate a seamless transition process of NGRN's.




\section{KEYWORDS}

nurse mentoring, new graduate registered nurses, clinical competence, job satisfaction, turnover, retention.

\section{INTRODUCTION}

Newly qualified nurses enter the workforce sometimes almost bereft of support [2] alongside mounting healthcare demands and patient complexity.[3] This situation creates a dilemma between theoretical expectations and practical realities, [4,5] and may develop into 'reality shock' and 'occupational stress'. [6] These factors lead to increased resignations and turnover [7]; correlating with new graduates' attrition rates of up to $60 \%$ during their first year of transition.[8] Because time and resources are invested during the transition phase, graduates' attrition becomes costly and improvident. [2]

Mentoring is an effective strategy that addresses the incongruence between theory and practice. Advocates of mentoring contend that it improves clinical competencies, job satisfaction and retention.[2] There are ongoing deliberations on the return on investment (ROI) of mentoring alongside outcomes in stabilising human resources.[9] To date, the content, structure, frequency, and duration of mentoring programs remain nonstandardised;[10] making recommendations and evaluations challenging.

There are various methods and structures deployed in the delivery of mentoring. Firstly, it can be established or developed, with the former based on the theoretical framework and implemented large-scale by more prominent companies.[9] The Versant Nurse Residency Program $[9,11]$ in the United States is an example with the latter established as a less-formal activity within smaller organisations.[6] Mentoring arrangements could either be in dyads, triads, or groups. The mentor-protégé dyad is a symbiotic partnership between experienced and novice nurses,.[6,12] A triad occurs when a peer mentor becomes supplementary support to the new graduate registered nurse (NGRN). [13] Group mentoring is cost-effective and provides frequent mentor interactions. [1 1]

Patient safety and skill mix trepidations [14] often confront nurse managers and organisational stakeholders, alongside the universal apprehensions of sustaining the nursing workforce's recruitment and retention.[15] With the burgeoning employment of NGRN's into the workforce, implementation of transitional support framework is vital to address potential gaps in patient care delivery and facilitate the seamless transition of new staff. $[3,14]$

This study aims to explore current data relating to mentoring effects on new graduate registered nurses' proficiencies, contentment, and retention.

\section{BACKGROUND}

There is currently an influx of novice nurses and a paucity of seasoned nurses who could potentially mentor them. $[5,16]$. This situation leads to new nurses feeling overwhelmed and dissuaded; and with the realisation of the contrary roles, 'reality shock' [6] sometimes presents itself. NGRN's experience a transitional period early in their career wherein they undergo role changes from being a student nurse to a registered nurse (RN). [5] This period is critical as it influences their clinical performance and career trajectory ). [17-19]

An NGRN is a fully qualified first-year RN who completed at least a three-year degree inclusive of a combination of university theoretical and practical components alongside hospital clinical placements. [20] The first year of embarking into the workforce is crucial for an NGRN as they often experience the inconsistencies between theoretical ideologies and practical realities. [20] If supported and managed appropriately, NGRN develops job satisfaction and work confidence, $[4,5,21]$ contributing to staff retention. [22] Conversely, mismanagement could lead to 'reality shock', [23] staff burnout and increasing turnovers. [24-25] The transition process is complicated, dynamic, and taxing to NGRN's. [5]

Benner's tenet on novice to expert model has influenced nursing practice since 1982. The model incorporates the Dreyfus Model of Skill Acquisition [26] and outlines how nursing skill acquisition develops over time. [27] Benner defines 'novice nurse' as an individual with no real-life nursing experience; therefore, they cannot exercise 'discretionary judgment', thereby necessitating recurrent 
prompting. [16] A novice relies on learned concepts and associated rules such as vital signs and nursing management of vital signs that fall outside of normal ranges, with inexperience to execute 'discretionary judgment' in delivering patient care, [16] associating fundamentalist concepts and practical realities become a challenge. Drusher [28] introduced the theory of transition, encompassing evolutionary periods of 'doing', 'being', and 'knowing', as experienced by NGRN's. These periods are like Kramer's theory of reality shock, as the nurse practitioner ventures from novice to expert, and can take up to 2 years. The novice nurse feels unqualified in performing the nursing role and delivering safe patient care. [29]

Mentoring, defined by Stewart and Krueger, cited in Mills, Francis, [30] is an expert-protégé nurse dyad characterised by reciprocal teaching and learning. [19] Mentoring aims to broaden knowledge base, improve professional practice, foster career progression, and retain staff. It can be a formal framework or an informal relationship; and entails sharing common goals and values between mentor and protégé. [31,32] Mentorship is different from preceptorship characterised by a supervisory, evaluative, and time-bound relationship between a novice and an experienced nurse. [33]

Clinical performance is defined as delivering safe, competent, appropriate, and timely clinical services by a health care provider to a patient with a particular health condition. It aims to accomplish desirable health outcomes and patient satisfaction. [34,35] Clinical performance is the continuous and perceptive application of skills and the subsequent reflection of practices.[36]

Job satisfaction is a sense of enjoyment and fulfilment derived from work, allowing the individual to feel motivated. It can be affected by various components related to tenure, such as leadership, colleagues, workload, and business model. [37,38]

Das and Baruah [22] found that employee retention is a structured approach with policies and procedures intended to create a culture that retains employees by meeting their diverse needs. It is a business strategy used to sustain workforce efficiency and attain organisational goals. [39]

As mentorship transcends the contractual and periodical limitations of preceptorship, [33] investigations of its effects on nurse retention, job satisfaction and competence become worthwhile. Awareness of the needs of progressing NGRNs enables colleagues, nurse managers, and organisations to make informed judgment to bolster protégés and foster positive workplace ethos. [10,40]

\section{RESEARCH QUESTIONS}

This study aims to answer the following research questions:

1. What are the effects of clinical mentoring on NGRNs' clinical performance?

2. What are the effects of clinical mentoring on NGRNs' job satisfaction?

3. What are the effects of clinical mentoring on NGRNs' job retention?

\section{SCOPE}

Only academic or scholarly English language articles published between 8 December 2015 to 8 December November 2020 that focused on mentoring of NGRN's and its effects on clinical competence, job satisfaction, and/or occupational retention are included. The reviewed literature encompassed nursing journal articles that were either peer-reviewed or refereed. The variety includes original journal articles and research, systematic and literature reviews, and case reports. The current review focuses on various mentoring approaches and structures executed to NGRN's working in direct patient care areas. A preliminary screen applied the selection criteria to cull the number of studies identified. Subsequently, a scoring tool designed by Kmet et al. [1] further scrutinises the quality of the remaining studies (Fig. 1, Fig. 2). Table 1 lists the inclusion and exclusion criteria.

\section{METHODS}

This study utilised a systematic literature review (SLR) as its research method, which encompasses critical perusal, systematic analysis and synthesis of published articles concerning mentoring and its effect on clinical performance, job satisfaction, and retention of NGRN's. It aids in understanding existing theories that serve as implementation bases of an intervention, outlines theoretical criticisms, maps existing evidence related to the main topic, identify gaps in the literature, and advise future research endeavours.

The authors used the Griffith University electronic library catalogue to search for relevant peer-reviewed, refereed, and scholarly articles. The Griffith University electronic library catalogue incorporates highly ranked, health- 
related academic databases such as MedLine, Cumulative Index to Nursing and Allied Health Literature, ScienceDirect, PubMed, Cochrane, ProQuest, EBSCOhost, and Scopus. Table 2 reproduces the search strings of keywords and Boolean operators and their results

The Preferred Reporting Items for Systematic Reviews and Meta-Analyses statement (PRISMA) [41] (Fig.1) was applied, to ensure transparency and comprehensive reporting on evidence-based strategies that can be used to inform future intervention modifications. [42]

Utilising the PRISMA statement, predetermined inclusion and exclusion criteria (Table 1) were used to evaluate the retrieved literature. Initial screening involved examining the title, then abstract and conclusions to establish if the article conformed to the current study's objectives. Articles with title, abstract and conclusions that contained words related to nurse mentorship and its effects on nurse graduates' clinical performance, job satisfaction and retention were included in the current study. These narrowed down the included articles as detailed in Fig. 1.

The remaining evidence was meticulously read and scored according to Standard Quality Assessment Scores (SQAS) [43] shown in Fig. 2 and Fig. 3 for quantitative and qualitative studies, respectively. Mixed method studies, however, have corresponding independently scored quantitative and qualitative sections. For studies to be eligible for SLR inclusion, corresponding Quantitative and Qualitative sections SQAS must be at least 18 and 16 , respectively. This step ensures the inclusion of only highquality literature. Table 4 lists qualified studies with high SQAS.

Table 1. Criteria utilised for inclusion and exclusion of articles in current review

\begin{tabular}{|c|c|}
\hline Inclusion criteria & Exclusion criteria \\
\hline Articles published between $8 / 12 / 2015$ to $8 / 12 / 2020$ & Grey literature \\
\hline $\begin{array}{l}\text { Nurse mentorship articles that mention its effects } \\
\text { on clinical performance, job satisfaction } \\
\text { and/or job retention }\end{array}$ & Nurse preceptorship articles \\
\hline Nursing discipline & SQAS Qualitative score $<16$ \\
\hline Academic or scholarly materials & SQAS Quantitative score $<18$ \\
\hline \multicolumn{2}{|l|}{ Peer-reviewed or refereed materials } \\
\hline \multicolumn{2}{|l|}{ Systematic reviews, meta-analyses and case reports } \\
\hline Articles published in English & \\
\hline
\end{tabular}

Table 2. Search keyword combinations and Boolean operators with corresponding search results (from 8 December 2015 to 8 December 2020)

\begin{tabular}{|c|c|c|c|}
\hline $\begin{array}{l}\text { Search keyword combinations } \\
\text { and Boolean operators }\end{array}$ & Article search results & $\begin{array}{l}\text { Article search results } \\
\text { (expanded beyond } \\
\text { Griffith } \\
\text { University website) }\end{array}$ & $\begin{array}{l}\text { Results used in } \\
\text { SLR }\end{array}$ \\
\hline "nurse mentor" & 270 & 276 & No \\
\hline $\begin{array}{l}\text { ("nurse mentor*") AND ("job satisfaction" OR "job retention") } \\
\text { AND ("clinical performance") }\end{array}$ & 2 & 2 & No \\
\hline $\begin{array}{l}\text { ("nurse mentor" ) AND ("job satisfaction" OR "job retention") } \\
\text { AND (("clinical performance") OR ("novice nurses") OR ("new } \\
\text { graduate } \\
\text { OR ("new graduate registered nurse")) }\end{array}$ & 30 & 30 & Yes \\
\hline
\end{tabular}




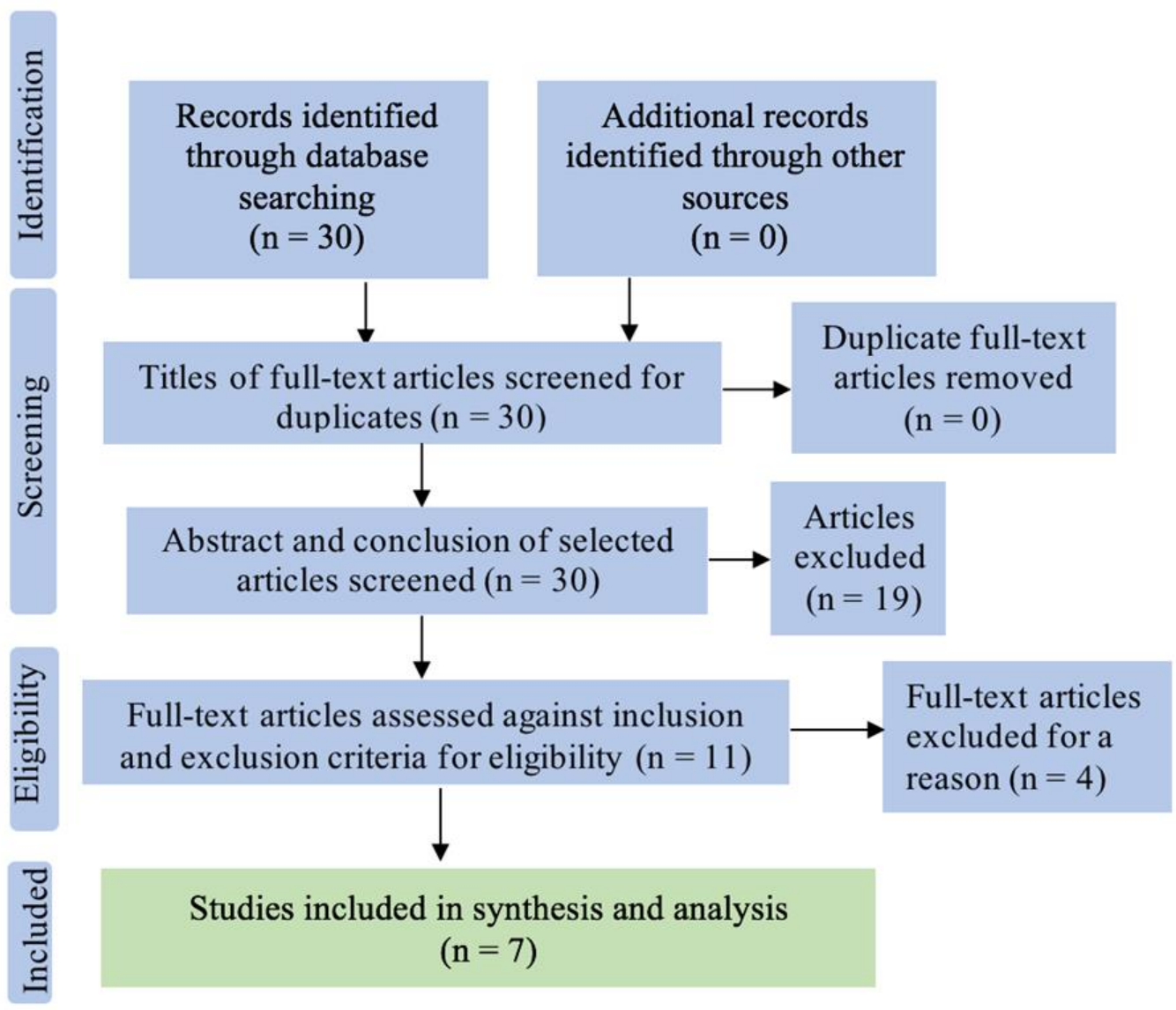

Fig. 1. Preferred Reporting Items for Systematic Reviews and Meta-Analyses (PRISMA) diagram showing a summary of findings at the outcome level.

FIGURE 2: STANDARD QUALITY ASSESSMENT SCORE (SQAS)

\begin{tabular}{|l|l|l|l|l|l|}
\hline \multicolumn{2}{|l|}{ Criteria } & $\begin{array}{l}\text { Yes } \\
\text { (2) }\end{array}$ & $\begin{array}{l}\text { Partial } \\
(1)\end{array}$ & No (0) & N/A \\
\hline 1 & Question / objective sufficiently described? & & & & \\
\hline 2 & Study design evident and appropriate? & & & & \\
\hline 3 & $\begin{array}{l}\text { Method of subject/ comparison group selection or source of information/ input } \\
\text { variables described and appropriate? }\end{array}$ & & & & \\
\hline 4 & Subject (and comparison group, if applicable) characteristics sufficiently described? & & & & \\
\hline 5 & If interventional and random allocation was possible, was it described? & & & & \\
\hline 6 & If interventional and blinding of investigators was possible, was it reported? & & & & \\
\hline 7 & If interventional and blinding of subjects was possible, was it reported? & & & & \\
\hline 8 & Outcome and (if applicable) exposure measure(s) well defined and robust to & & & & \\
\hline 9 & measurement / misclassification bias? Means of assessment reported? & & & & \\
\hline 10 & Anample size appropriate? & & & & \\
\hline 11 & Some estimate of variance is reported for the main results? & & & & \\
\hline 12 & Controlled for confounding? & & & & \\
\hline 13 & Results reported in sufficient detail? & & & \\
\hline 14 & Conclusions supported by results? & & & \\
\hline
\end{tabular}

Fig. 2 Standard Quality Assessment Score (SQAS). Checklist for assessing the quality of quantitative studies. Source: Kmet, Lee ${ }^{25}$. The summation of individual scores for 'yes', 'partial', and 'no' were attributed to each quantitative study included in this review, as outlined in Table 3. Quantitative SQAS range from 0 to 28 , indicating low quality and high quality, respectively. 


\begin{tabular}{|l|l|l|l|l}
\hline \multicolumn{2}{|l|}{ Criteria } & Yes (2) & Partial (1) & No (0) \\
\hline 1 & Question / objective sufficiently described? & & & \\
\hline 2 & Study design evident and appropriate? & & & \\
\hline 3 & Context for the study clear? & & & \\
\hline 4 & Connection to the theoretical framework/wider body of knowledge? & & & \\
\hline 5 & 5. Sampling strategy described, relevant and justified? & & & \\
\hline 6 & Data collection methods clearly described and systematic? & & & \\
\hline 7 & Data analysis clearly described and systematic? & & & \\
\hline 8 & Use of verification procedure(s) to establish credibility? & & & \\
\hline 9 & Conclusions supported by results? & & & \\
\hline 10 & Reflexivity of the account? & & & \\
\hline
\end{tabular}

Fig. 3 Standard Quality Assessment Score (SQAS). Checklist for assessing the quality of qualitative studies. Source: Kmet, Lee ${ }^{25}$. The summation of individual scores for 'yes', 'partial', and 'no' were attributed to each quantitative study included in this review, as outlined in Table 3. Qualitative SQAS range from 0 to 20 , indicating low quality and high quality, respectively.

\section{LITERATURE REVIEW}

All the reviewed publications support the effectiveness of mentoring as a transitional approach for NGRN's. $[5,6,9,11,13,19,44]$ The majority of these studies report positive effects of clinical mentoring on NGRNs' job satisfaction, clinical performance, and retention. An exception to this is the article by Ackerson and Stiles [9] who contend that professional satisfaction plummeted, possibly due to feelings of detachment or lack of feelings of competency halfway and towards the end of a 1 -year (NRP) Nurse Residency Program (Table 4). Zhang, Qian [6] encountered a study that did not see any difference in job satisfaction levels between mentoring program participants and non-participants.

Table 3. Articles identified referring to mentorship

\begin{tabular}{lll}
\hline Research design & Number & Articles \\
Quantitative & 3 & $\begin{array}{l}\text { Baumann, Hunsberger, Crea-Arsenio, et al. } \\
\text { Williams, Scott, Tyndall, et al. } \\
\text { Zhang, Qian, Wu, et al., }\end{array}$ \\
Qualitative & 2 & $\begin{array}{l}\text { Gellerstedt, Moquist, Roos, et al. } \\
\text { Mcinnes, Halcomb, Huckel, et al. }\end{array}$ \\
Mixed methods & 2 & $\begin{array}{l}\text { Ackerson and Stiles } \\
\text { Verret and Lin }\end{array}$ \\
\end{tabular}


Table 4. Mentoring articles included in review

Studies with Quantitative and Qualitative SQAS of at least 18 and 16 , respectively, were included in the study

\begin{tabular}{|c|c|c|c|c|c|c|}
\hline Authors & Main findings & $\begin{array}{l}\text { Mentoring effects on job } \\
\text { satisfaction }\end{array}$ & $\begin{array}{l}\text { Mentoring effects on } \\
\text { performance }\end{array}$ & $\begin{array}{l}\text { Mentoring effects on job } \\
\text { retention }\end{array}$ & $\begin{array}{l}\text { Quantitative } \\
\text { SQAS }\end{array}$ & $\begin{array}{l}\text { Qualitative } \\
\text { SQAS }\end{array}$ \\
\hline $\begin{array}{l}\text { Ackerson } \\
\text { and Stiles }\end{array}$ & $\begin{array}{l}\text { Many unprepared novice nurses cannot meet work demands, resulting } \\
\text { to stress and turnover. } \\
\text { Nurse residency program (NRP) provides mentorship and peer support. } \\
\text { NRP effectiveness is dependent on content rather than structure. } \\
\text { Retention was unsustained at second year, possibly attributed to } \\
\text { mentorship inapplicability to NGRN's. Mitigating strategies }\end{array}$ & $\begin{array}{l}\text { Job satisfaction fell, probably } \\
\text { due to disengagement or } \\
\text { incompetency at } 6 \text { and } 12 \\
\text { months of NRP. }\end{array}$ & $\begin{array}{l}\text { Autonomous clinical } \\
\text { decision making. } \\
\text { Improved stress } \\
\text { management and } \\
\text { communication skills. }\end{array}$ & $\begin{array}{l}\text { NRP has positive return } \\
\text { on investment (ROI) } \\
\text { (increases retention rates; } \\
\text { reduces turnover, } \\
\text { recruitment and } \\
\text { replacement fees) }\end{array}$ & 22 & 19 \\
\hline
\end{tabular}

include 15-month Wisconsin NRP and optional exploration phase program.

Baumann, NGRNs' unreadiness in joining the workforce is a worldwide concern.

et al. Consistent and extended Transition programs (TP's) improve care quality.

Compared to non-participants, TP participants have higher key dimensions of care delivery scores that improve over time. Mentorship standardisation and best practices remain inconsistent.

Gellerstedt, NGRN transition to independent RN role is stressful.

et al. Senior nursing staff turnover has led to NGRN role transition issues and loss of mentorship figures.

An advocating trainee program and transformational leadership style aid in NGRN's role transition to RN roles.

NGRN's have higher expectations from management during the orientation phase of the transition period.

An accessible and versatile manager is needed to support NGRN's during the transition phase.

An established agreement between nurse managers and nurse educators regarding NGRN competencies and knowledge base will assist in NGRNs' understanding of their roles
TP's bridge the gap between education and practice, which foster job satisfaction.

TP's augment job fulfillment.

TP participants had increased job satisfaction.

Trainee program and transformational leadership lead to job satisfaction

\section{An introduction during the} orientation phase provides avenues for NGRN's to ask questions and improves the delivery of safe patient care.

Confidence is gained secondary to NGRN's conversing with superiors

NGRN's noted the need to revise tutoring and work introduction in order to address the theory-practice discrepancy
Increases retention rates; 24

N/A minimises staff turnover.

Trainee program and

transformational

leadership lead to staft

retention.

NGRN's realise their role

in replacing seasoned

nurses when they retire

Concerns about patient

safety are documented to

be the reasons for

NGRN's resignations

during their first year of

practice

Table 4. (continued)

\begin{tabular}{|c|c|c|c|c|c|c|}
\hline Authors & Main findings & $\begin{array}{l}\text { Mentoring effects on job } \\
\text { satisfaction }\end{array}$ & Mentoring effects on performance & Mentoring effects on job retention & $\begin{array}{l}\text { Quantitative } \\
\text { SQAS }\end{array}$ & $\begin{array}{l}\text { Qualitative } \\
\text { SQAS }\end{array}$ \\
\hline $\begin{array}{l}\text { Mclnnes, et } \\
\text { al. }\end{array}$ & $\begin{array}{l}\text { New graduate transition programs in New Zealand and } \\
\text { Australia focus on attracting NGRN's into } \\
\text { Primary Health Care (PHC). } \\
\text { Nurse mentors in general practice (GP) settings are } \\
\text { confronted with barriers related to time } \\
\text { management and funding. } \\
\text { Recruitment-retention strategies are geared more } \\
\text { towards nurses working in acute care } \\
\text { settings. } \\
\text { Lower remuneration rates and negative perceptions } \\
\text { regarding nurses' roles in GP work affect job } \\
\text { retention rates of PHC nurses. } \\
\text { There is ample documentation of transitional changes } \\
\text { experienced by NGRN's in acute care } \\
\text { settings leading to poor job retention and } \\
\text { lower job satisfaction. Studies not seen in } \\
\text { PHC. }\end{array}$ & $\begin{array}{l}\text { NG program satisfaction and } \\
\text { nurse career progression } \\
\text { noted } \\
\text { Mentors also learned from } \\
\text { mentees }\end{array}$ & $\begin{array}{l}\text { Honed a wider range of clinical } \\
\text { skills GP } \\
\text { Developed confidence in initiating } \\
\text { new programs and fostered work } \\
\text { independence }\end{array}$ & $\begin{array}{l}\text { NG program in GP sector can } \\
\text { ameliorate nursing workforce } \\
\text { shortages. } \\
\text { NGRN's who completed the NG } \\
\text { program expressed strong desires to } \\
\text { remain working in GP settings }\end{array}$ & N/A & 16 \\
\hline $\begin{array}{l}\text { Verret and } \\
\text { Lin }\end{array}$ & $\begin{array}{l}\text { 'Generational mentoring' solidifies relationships, } \\
\text { bridges generational gaps, and breeds new } \\
\text { mentors. } \\
\text { Overall staff responsibility to mentor NGRN's. } \\
\text { Managerial support perpetuates mentoring and high } \\
\text { practice standards. } \\
\text { Delineates roles of preceptor (instructive/evaluative); } \\
\text { mentor (supportive); and facilitator } \\
\text { (coordinator/mentor-mentee matcher). } \\
\text { Traditional mentorship is intensive and exclusive. } \\
\text { Contemporary mentorship is supportive, caring, } \\
\text { pleasurable and satisfying. } \\
\text { Mentor characteristics stated (i.e., confident advisor; } \\
\text { participative teacher; development-oriented; } \\
\text { aspirational thinker). }\end{array}$ & $\begin{array}{l}\text { Job satisfaction resulting } \\
\text { from positive effects of } \\
\text { Generational approach to } \\
\text { mentoring. } \\
\text { Job satisfaction ensues from } \\
\text { continuity of mentoring and } \\
\text { delivery of high standards of } \\
\text { care. } \\
\text { Job satisfaction associated } \\
\text { with decreased turnover and } \\
\text { increased retention. }\end{array}$ & $\begin{array}{l}\text { Nurtures professional growth; } \\
\text { promotes high quality nursing } \\
\text { practice; increases optimal patient } \\
\text { outcomes; decreases stress; } \\
\text { facilitates transition to independent } \\
\text { roles; empowers communication; } \\
\text { develops leadership skills; and } \\
\text { improves confidence. } \\
\text { Mentorship necessary to cope with } \\
\text { health care demands }\end{array}$ & $\begin{array}{l}\text { Stabilises human resource base. } \\
\text { Decreases turnover and improves } \\
\text { retention rates (as a result of } \\
\text { enculturation and job satisfaction). }\end{array}$ & 18 & 17 \\
\hline
\end{tabular}




\begin{tabular}{|c|c|c|c|c|c|c|}
\hline Authors & Main findings & $\begin{array}{l}\text { Mentoring effects on job } \\
\text { satisfaction }\end{array}$ & Mentoring effects on performance & Mentoring effects on job retention & $\begin{array}{l}\text { Quantitative } \\
\text { SQAS }\end{array}$ & $\begin{array}{l}\text { Qualitative } \\
\text { SQAS }\end{array}$ \\
\hline $\begin{array}{l}\text { Williams, et } \\
\text { al., }\end{array}$ & $\begin{array}{l}\text { Precepting and mentoring differentiated. } \\
\text { Mentorship is less commonly used in NRP's. } \\
\text { Skill development and turnover are collectively } \\
\text { measured by perceptions of comfort in } \\
\text { assuming nursing roles. } \\
\text { Turnover intention is correlated to discomfort in } \\
\text { nursing practice. } \\
\text { Suggests later (period of) mentorship applicability, after } \\
\text { NGRN's gain skill and proficiency. }\end{array}$ & $\begin{array}{l}\text { NRP's and mentoring } \\
\text { generally stimulate job } \\
\text { satisfaction. } \\
\text { Standardised NRP's bring } \\
\text { about higher levels of job } \\
\text { satisfaction. }\end{array}$ & $\begin{array}{l}\text { Mentoring not related to skill } \\
\text { development; } \\
\text { Group mentoring is cost-effective } \\
\text { in facilitating transition due to } \\
\text { minimal monetary and resource } \\
\text { demands; and } \\
\text { One-to-one mentoring is } \\
\text { efficacious yet expensive strategy } \\
\text { in promoting stress management, } \\
\text { professional development and } \\
\text { facilitating practice transition. }\end{array}$ & $\begin{array}{l}\text { Mentoring not established to be } \\
\text { associated with turnover; although } \\
\text { turnover intention likely higher or } \\
\text { definite in group mentees receiving } \\
\text { less than four mentor encounters. } \\
\text { Despite increasing use of NRP's, } \\
\text { turnover rates in the first nursing job } \\
\text { are not considerably ameliorated. }\end{array}$ & 21 & $N / A$ \\
\hline $\begin{array}{l}\text { Zhang, et } \\
\text { al. }\end{array}$ & $\begin{array}{l}\text { Mentoring and precepting separately defined. } \\
\text { Mentoring program components, such as practical and } \\
\text { psychological support, have affirmative } \\
\text { contributions to mentors, mentees, and } \\
\text { healthcare organisations. These create a } \\
\text { supportive workplace environment. } \\
\text { An effective mentoring program encompasses } \\
\text { meticulous selection and comprehensive } \\
\text { training of mentors; but is not devoid of } \\
\text { hurdles (i.e., varying schedules, space and } \\
\text { time constraints). } \\
\text { Results guide nurse managers in planning, executing, } \\
\text { and modifying NGRN mentoring programs. }\end{array}$ & $\begin{array}{l}\text { Job satisfaction reviewed } \\
\text { quantitively and qualitatively } \\
\text { by } 2 \text { studies each. Overall } \\
\text { job satisfaction increased } \\
\text { after mentoring, but took } 18 \\
\text { months to attain it. } \\
\text { One study found that there } \\
\text { was no difference in the } \\
\text { levels of job satisfaction } \\
\text { between mentor and non- } \\
\text { mentor groups. }\end{array}$ & $\begin{array}{l}\text { Improves nursing competency. } \\
\text { Mentoring programs proven } \\
\text { effective in facilitating transition to } \\
\text { practice. }\end{array}$ & $\begin{array}{l}\text { Mentoring programs can: } \\
\text { 1. Decrease turnover rate; and } \\
\text { 2. Increase retention rates. }\end{array}$ & 20 & N/A \\
\hline
\end{tabular}

After mentoring, evidence of clinical performance development includes autonomous clinical decision making; $[5,19,13]$ work independence and confidence in initiating new programs; [19] improved stress management; $[9,11,13]$ better communication skills, [5,9,44] broader clinical skills; [19] and confidence in seeking assistance from colleagues. [13] Nursing skills and leadership traits have improved, [6,13] thereby optimising patient care outcomes,[13] spurring competency, [6,11] confidence [11] and maintaining high-quality practise standards. [13] Job satisfaction has emerged from increased interaction in NRP settings [11] and closing the disparities between education and practice.[44] It ensures the consistent delivery of high standards of care [13] and patient safety.[5] Job satisfaction was also found to ensure from the NGRN trainee program and a transformational leadership approach.[5]

There is a link between retention and turnover. A literature review revealed that retention and turnover are used interchangeably, as terminologies and as measures of mentoring effectiveness. [6] Conversely, Ackerson and Stiles [9] found no literature source that defined both terms.
However, Williams, Scott [11] preferred turnover to retention, asserting that the latter is easily understood. Retention is described as a collective term reflective of influencing factors that encourage or hinder job satisfaction. In terms of measuring parameters over time, turnover rates during the first year is around $20 \%$ to $70 \%$, [6] with resignations related to NGRNs' concerns about their ability to maintain patient safety; [5] whilst 17\% of NGRN's leave, [44] with attrition or job-change rates surging to $31 \%$ at the end of third year. [44]

Verret and Lin [13] determined that retention creates a positive return on investment (ROI). In acute settings, minimal recruitment and replacement expenditures drive ROI, [9] determined by turnover rates. [11] Furthermore, NRP, mentoring partnerships, and transitional practice programs (TPP) decrease turnover rates, $[6,11]$ contribute to job retention [19] and address nursing workforce shortages. [19] Williams, Scott [11] collectively measured the best ROI indicators: skill development and turnover. However, and found that turnover rates in the first nursing jobs do not ameliorate turnover intentions. Williams, Scott [11] and Ackerson and Stiles [9] quantified the incurred 
costs per resignation and turnover, amounting to approximately $\$ 60,000$ and $\$ 71,000$, respectively. Mclnnes, Halcomb [19] noted that the gearing of recruitmentretention strategies is more towards nurses working in acute care settings than in primary health care (PHC).

Regarding precepting and mentoring, these roles are delineated by most included literature, $[6,11,13]$ with role clarification of a facilitator, focusing on mentorship coordination and pairing. [13] However, an SLR conducted by Zhang, Qian [6] found that both terms are not clearly defined by moststudies previously examined.

After reviewing the literature, different contrasting structures of mentoring emerged such as formal and informal mentoring; [6,9] one-to-one [6,11] and group mentoring; [1 1] and established and internally developed programs. [9] Formal mentoring has structure, pre-set goals and timeframes, whilst informal mentoring is a mutually agreed mentor-protégé pairing.[6] One-to-one and group mentoring structures are self-explanatory; however, the former is costly, while the latter offers frequent meetings. [11] Established and internally developed mentoring programs are constructed according to a chosen theoretical framework. One is developed locally by smaller businesses, whilst the other is a structured, standardised and evidence-based programme utilised by larger organisations, [1 1, 45] respectively.

The seven articles reviewed focused on a specific mentoring program. In the United States, NRPs $[9,11]$ and the generational mentorship approach [13] are gaining popularity as forms of established mentorship. At the same time, transitional practice programs (TPP's) are applied in China, [6] Australia and New Zealand, [19] Sweden, [5] and Canada. [44]

The mentoring models also differ, ranging from established programs like Versant NRP University Health System Consortium/American Association of Colleges and Nursing Program, [9,11] and Wisconsin NRP [9] grounded on Benner's novice to expert model [16] and Duchsher's transition theory. [28]

Formal and informal mentoring programs are offered separately in TPP. [6] At the same time, NRP delivers them jointly, with possible views of extending the mentoring relationship to informal, following the formal component. [9] Additionally, extended TPP is made available by the
Canadian government of up to 6 years post-graduation of NGRN's who require more transitional nursing role support. [44] Conversely, generational mentoring helps develop future mentors and is enriching to both mentor and mentee, as workplace generational diversity is acknowledged and utilised. [13]

Zhang, Qian et al. [6] suggested Verret and Lin [13] cited mentor characteristics, whilst mentor education qualifications. Only one study mentioned resource materials compiled for mentoring, which is part of the seminal innovative mentor cohort, commenced in winter of 2013. [13] These reflect the early stages of mentorship provision. Job satisfaction of mentees is linked to a transformation leadership approach. [5]

Further exploration of mentor-mentee combinations reveals the practices of one-to-one mentoring, [6,11] a supportive relationship between senior and junior nurses. The novice-peer mentor-veteran mentor triad [13] facilitates symbiotic relationship learning. Here, experienced nurses learn lifework balancing skills from their mentees, while the latter supports honing clinical skills and decision-making.

Reviewing the latest available literature showed how dynamic mentoring approaches have emerged to accommodate changes in the healthcare environment and patient acuity. Firstly, mentoring is now seen as enjoyable; [13] distinctive from traditional mentoring views which portray mentoring as exclusive and intensive. [12] Communication between parties has transcended into text messaging, emailing, calling, updating social media sites, [6] and informal meetings over coffee or meals.[13]

Terminologies have also metamorphosed, paralleling the direction of mentoring. For instance, NGRN's are also referred to as "advanced beginners", reflecting the progression of skill development and knowledge building. [6] "Occupational stress" [6,46] and "reality shock" $[6,47]$ are coined to describe anxious feelings due to overwhelming job demands, and realisation of discrepancies between theory and practice, respectively. $[7,6]$

There are gaps in the literature that require further exploration.Zhang, Qian [6] proposed mentorship-focused studies to have at least 60 participants to minimise bias and increase generalisability of results. Furthermore, they 
suggested determining best practices for mentorship; exploring the qualitative views on the value of mentorship: comparing the feasibility of different mentorship types and alternatives; and determining the frequency of mentor contact to achieve the desired outcomes. [6] Mentors must set minimum educational standards, whilst mentees need their transitional phase needs identified and prioritised, so management and mentors can collaborate on establishing a framework that helps meet these goals. [6] A standardised protocol that indicates timeframes and milestones will be valuable in guiding the progression of availing precepting and mentoring support. A preceptor is applicable during intensive skill development, whilst a mentor is appropriate for broadening career horizons. [1 1] Lastly, the analysis of obtained information reveals a few flaws in the currently available literature. Firstly, a theoretical framework like Benner's theory [27] may need content realignment to contemporary practice and setting, [9] as it contains outdated information that may be irrelevant to current nursing practice. For example, the description of a novice nurse's tasks is knowing the normal parameters of vital signs to detect problems. [16,27] Today's patients present with complex morbidities that may masquerade clinical signs presentation, deviating from what theory suggests. Healthcare has deviated into a globalised form, facing overwhelming demands whilst delivering preventative and patient-centred care. [48]

The interconnectedness between retention and turnover is not a reciprocal relationship. The same holds with precepting and mentoring. These terms are often transposed in the literature and assume reciprocity and provide no definition. The paucity of evidence-based practices presents to nurse managers and healthcare organisations a challenge and perpetuate the adjustment challenges confronting NGRN's. This situation explains the decreased number of mentoring practices in place [13] and the increasing turnover rates of NGRN's.

\section{DISCUSSION}

The literature review demonstrated three recurrent themes emerging from the studies:

1. The value of the informal structure of mentoring programs.

2. The duration of mentoring programs; and

3. The effectiveness of mentoring programs towards participants and organisations.
Contemporary mentoring has assumed a less-formalised structure that requires substantial participant involvement. It incorporates a range of communication pathways ranging from text messaging to informal gatherings. Mentoring facilitates the holistic development of NGRN's whilst assisting them in transitioning into professional practice. A novel mentoring method, called the generational approach, hones mentees and fosters future mentors. [13]

The literature differentiates preceptorship and mentoring. [13] The former could be utilised short-term, during the initial phases of skill honing. Transitioning into the latter happens once the NGRN has established a skill and knowledge base, given the long-term, holistic learning that is broader in scope. This situation parallels the analogy that preceptorship is imperative employment and mentoring develops the NGRN holistically after employment. [1 1]

The timeframe associated with mentoring is long-term. However, studies did not show a uniform duration of mentoring programs. They vary from 1 to 6 years after graduation, whereas the current studies focus on the first three years of practice $[5,6,9,11,13,19,44]$.

Mentoring effectiveness is portrayed in two avenues of cost-effectiveness and job satisfaction, derived by the organisation and NGRN's, respectively. Cost-effectiveness or ROI is predominant until the end of the first year of mentorship; $[13,46]$ correlating with plummeting retention rates at year two [9] and rising resignation and career changes at year three. [44] This situation necessitates the formulation of qualitative tools that would assist health managers, and key stakeholders explore the factors that contribute to such changes and generate mitigating strategies that can be effectively implemented towards the end of year one.

Job satisfaction reflects multi-faceted avenues including improved clinical competence [6], high care standards [13], congruence of practice and learning and consistent mentoring [13]. It contributes to job retention and turnover. $[6,9,11,13,44]$ New studies show trending disconnection and ineptness of NGRN's from 6 months to 1 year of undergoing mentoring, leading to lower job satisfaction. [9] Further exploration of factors causing these deviations is crucial, so mentors can look out for emerging changes and intervene immediately. 


\section{RECOMMENDATIONS/GAPS IN THE LITERATURE}

This SLR has identified four gaps in the literature to guide future research endeavours that focus on mentoring.

1. The literature on mentorship is seminal and requires quantitative nor qualitative clinical performance indicators that measure NGRN competency before and after mentorship. These will serve as standardised benchmarks for nurse mentors, nurse managers, and healthcare organisations to use when deciding on implementing mentoring programs to NGRN's.

2. There is no standardised structure that guides the best practice in mentoring programs and sparks a debate about program content rather than structure determining its effectiveness. [9] Another study argues that group mentoring, and more frequent meetings enhance the effectiveness of TP's. [11] With the probable inception of indicator tools, [9] benchmarks and timeframes will provide evidence-based guidance regarding the content, duration, frequency, and structure of mentoring programs. [10] Content should reflect the learning needs and milestones of mentees. Exploring content being either standardised for generalised implementation or tailored according to individual learning plans could be beneficial. [10] Refinement of mentor-mentee pairings [13] will predetermine matches based on mutual characteristics and goals, or by the mentee's choice.

3. Contemporary literature examines job satisfaction, retention-turnover, and clinical performance, but there have not been any large-scale studies reported in the literature. There is a need for a more rigorous, formal research into the effectiveness of mentoring programs, including cost-effectiveness.

4. The literature search revealed that there is mentorshiprelated research paucity in non-acute care settings like PHC. It is recommended that mixed methods research that explores the personal views of NGRNs regarding mentorship in community settings and develops a standardised duration of the mentorship program for PHC NGRNs. Since the pre-existing mentorship strategies to promote job satisfaction, competence, and job retention are dedicated to NGRNs working in acute care. These strategies may be deemed inapplicable to NGRNs in non-acute care settings.
The included studies came from the United States, [9, 11 , 13] Canada, [44] Australia and New Zealand, [19] Sweden, [5] and China. [6] Studies from other countries did not meet inclusion criteria, contracting the pertinence of results. The writers recommend that a large-scale quantitative study that will increase the generalisability and applicability of results. A qualitative study can focus on contributing factors to NGRNs' decisions related to their staying or leaving their position after the transitional period.

\section{CONCLUSION}

Mentoring is a novel and effective transitional approach for NGRNs compared to precepting contractual and timebound conditions. Mentorship informality brings about long-term effects that transcend into the quality of professional competence and relationships. In general, clinical mentoring increases the NGRNs' job satisfaction, retention, and clinical performance.

\section{References}

1. Kmet L, Cook L, Lee R. Standard Quality Assessment Criteria for Evaluating Primary Research Papers from a Variety of Fields. University of Alberta Libraries 2004.

2. Phillips C, Esterman A, Kenny A. The theory of organisational socialisation and its potential for improving transition experiences for new graduate nurses. Nurse Educ Today. 2015;35(1):118-24.

3. Hussein R, Everett B, Ramjan LM, Hu W, Salamonson Y. New graduate nurses' experiences in a clinical specialty: a follow up study of newcomer perceptions of transitional support. BMC Nurs. 2017;16:42.

4. Ortiz J. New graduate nurses' experiences about lack of professional confidence. Nurse Education in Practice. 2016;19:19-24.

5. Gellerstedt L, Moquist A, Roos A, Karin B, Craftman AG. Newly graduated nurses' experiences of a trainee programme regarding the introduction process and leadership in a hospital setting-A qualitative interview study. J Clin Nurs. 2019;28(9-10):1685-94.

6. Zhang $Y$, Qian $Y$, WU J, Wen F, Zhang Y. The effectiveness and implementation of mentoring program for newly graduated nurses: A systematic review. Nurse Educ Today. 2016;37:136-44. 
7. Walker A, Costa BM, Foster AM, de Bruin RL. Transition and integration experiences of Australian graduate nurses: A qualitative systematic review. Collegian. 2017;24:505-12.

8. Goode CJ, Lynn MR, McElroy D, Bednash GD, Murray B. Lessons learned from 10 years of research on a post-baccalaureate nurse residency program. J Nurs Adm. 2013;43(2):73-9.

9. Ackerson K, Stiles KA. Value of Nurse residency Programs in Retraining New Graduate Nurses and Their Potential Effect on the Nursing Shortage. Journal of Continuing Education in Nursing. 2018;49(6):282-8.

10. Matin SA. Understanding Effective Mentoring in Nursing Education: The Relational-Reliant Concept. JOJ Nurse Health Care. 2017;2(5):1-3.

11. Williams FS, Scott ES, Tyndall DE, Swanson M. New Nurse Graduate Residency Mentoring: A Retrospective Cross-Sectional Research Study. Nurse Economic $\$ .2018 ; 36(3): 121-7$.

12. Vatan F, Temel AB. A Leadership Development Program Through Mentorship for Clinical Nurses in Turkey. Nursing Economic\$. 2016;34(5):242-50.

13. Verret G, Lin V. Easing the Transition: An Innovative Generational Approach to Peer Mentoring for New Graduate Nurses. J Pediatr Nurs. 201 6:31 (6):745-56.

14. Andrews DR, Dziegielewski SF. The nurse manager: job satisfaction, the nursing shortage and retention. J Nurs Manag. 2005;13(4):286-95.

15. Tomietto M, Rappagliosi CM, Sartori R, Battistelli $A$. Newcomer nurses' organisational socialisation and turnover intention during the first 2 years of employment. J Nurs Manag. 2015;23(7):851-8.

16. Benner PE. From novice to expert: excellence and power in clinical nursing practice. Menlo Park, Calif: Addison-Wesley, Nursing Division; 1984.

17. Cylke K. Needs assessment: blueprint for a nurse graduate orientation employer toolkit. J Nurses Staff Dev. 2012;28(2):57-61.

18. Feng RF, Tsai YF. Socialisation of new graduate nurses to practising nurses. J Clin Nurs. 2012;21 (13-14):2064-71.

19. Mclnnes S, Halcomb E, Huckel K, Ashley C. Experiences of registered nurses in a general practicebased new graduate program: a qualitative study. Aust J Prim Health. 2019;25(4):366-73.

20. Gardiner I, Sheen J. Graduate nurse experiences of support: A review. Nurse Educ Today. 2016:40:7-12.
21. Malouf N, West S. Fitting in: a pervasive new graduate nurse need. Nurse Educ Today. 2011 1;1 (5):488-93.

22. Das BL, Baruah M. Employee Retention: A Review of Literature. J Bus Manag. 2013;14(2):8-16.

23. Mellor P, Gregoric C. Ways of Being; Preparing Nursing Students for Transition to Professional Practice. Journal of Continuing Education in Nursing. 201 6;47(7):330-40.

24. Rudman A, Gustavsson JP. Early-career burnout among new graduate nurses: A prospective observational study of intra-individual change trajectories. International Journal of Nursing Studies. $2011 ; 48(3): 292-306$.

25. Freeling $M$, Parker $S$. Exploring experienced nurses' attitudes, views and expectations of new graduate nurses: a critical review. Nurse Educ Today. 2015;35(2):e42-9.

26. Dreyfus SE, Dreyfus HL. A five stage model of the mental activities involved in directed skill acquisition: Stoming Media; 1980.

27. Davis A, Maisano P. Patricia Benner: novice to expert-a concept whose time has come (again). Oklahoma Nurse. 2016;61 (3):13.

28. Duchscher JB. A process of becoming: the stages of new nursing graduate professional role transition. $J$ Contin Educ Nurs. 2008;39(10):441-50; quiz 51-2, 80.

29. Kramer M. Reality shock: why nurses leave nursing. St. Louis, MO: C.V. Mosby Company; 1974.

30. Mills J, Francis K, Bonner A. Getting to know a strangerrural nurses' experience of mentoring: A grounded theory. International Journal of Nursing Studies. 2008:45:599-607.

31. Nickitas DM. Mentorship in Nursing: An Interview with Connie Vance. Nursing Economic\$. 2014;32(2):65-9.

32. Huang $\mathrm{CY}$, Weng RH, Chen YT. Investigating the relationship among transformational leadership, interpersonal interaction and mentoring functions. J Clin Nurs. 201 6;25(15-16):2144-55.

33. Dickerson PS, Lubejko BG, Crew CL. Personality and Mentoring: Stepping Off on the Right Foot. Journal of Continuing Education in Nursing. 2016;47(5):201-3.

34. WHO Centre for Health Development. A Glossary of Terms for Community Health Care Services for Older Persons: World Health Organization Centre for Health Development; 2014. 
35. Healthcare NCoQaSi. Clinical performance and effectiveness Sydney, NSW: ACSQHC; 2018 [4

December 2018]. Available from:

https://www.nationalstandards.safetyandquality.gov. av/1.-clinical-governance/clinical-performance-andeffectiveness.

36. Epstein RM, Hundert EM. Defining and assessing professional competence. JAMA. 2002;287(2):226-35.

37. Liu Y, Aungsuroch Y, Yunibhand J. Job satisfaction in nursing: a concept analysis study. Int Nurs Rev. 2016;63(1):84-91.

38. Aziri B. Job Satisfaction: a literature review. Manag Res Prac. $2011 ; 3(4): 77-86$.

39. Mita M, Aarti K., Ravneeta D. Study on Employee Retention and Commitment. International Journal of Advance Research in Computer Science and Management Studies. 2014;2:154-64.

40. Jokelainen M, Tossavainen K, Jamookeeah D, Turunen $H$. Seamless and committed collaboration as an essential factor in effective mentorship for nursing students: conceptions of Finnish and British mentors. Nurse Education Today. 2013;33(5):437-43.

41. Moher D, Liberati A, Tetzlaff J, Altman D. Preferred reporting items for systematic reviews and metaanalyses: the PRISMA statement. Journal of Clinical Epidemiology. 2009;62:1006-12.

42. Liberati A, Altman DG, Tetzlaff J, Mulrow C, Gotzsche PC, loannidis JP, et al. The PRISMA statement for reporting systematic reviews and meta-analyses of studies that evaluate health care interventions: explanation and elaboration. PLOS Med. 2009;6(7):e1000100.

43. Kmet LM, Lee RC, Cook LS. Standard Quality Assessment criteria for Evaluating Primary Research Papers. Edmonton, Alberta: Health Technoogy Assessment Unit Alberta Heritage Foundation for Medical Research; 2004. p. 1-31.

44. Baumann A, Hunsberger M, Crea-Arsenio M, AkhtarDanesh N. Policy to practice:Investment in transitioning new graduate nurses to the workplace. J Nurs Manag. 2018;26(4):373-81.

45. Versant Healthcare Competency Solutions. The best workforce for the best healthcare: Versant Holdings LLC; 2018 [Available from: https://www.versant.org/human-resources-solutions/.
46. Labrague LJ, McEnroe-Petitte DM. Job stress in new nurses during the transition period: an integrative review. Int Nurs Rev. 2018;65(4):491-504.

47. Sparacino LL. Faculty's Role in Assisting New Graduate Nurses' Adjustment to Practice. SAGE Open Nursing. 2016;2:1-9.

48. Mittelman M, Hanaway P. Globalization of Healthcare. Glob Adv Health Science. 2012;1 (2):5-7. 